\title{
An update on magnesium and bone health
}

\author{
Mariangela Rondanelli • Milena Anna Faliva - Alice Tartara • Clara Gasparri • \\ Simone Perna • Vittoria Infantino · Antonella Riva • Giovanna Petrangolini • \\ Gabriella Peroni
}

Received: 19 June 2020/Accepted: 28 December 2020/Published online: 6 May 2021

(C) The Author(s) 2021

\begin{abstract}
In 2009 EFSA Panel concludes that a cause and effect relationship has been established between the dietary intake of magnesium $(\mathrm{Mg})$ and maintenance of normal bone. After 2009, numerous studies have been published, but no reviews have made an update on this topic. So, the aim of this narrative review was to consider the state of the art since 2009 on relationship between Mg blood levels, $\mathrm{Mg}$ dietary intake and $\mathrm{Mg}$ dietary supplementation (alone or with other micronutrients; this last topic has
\end{abstract}

M. Rondanelli

IRCCS Mondino Foundation, 27100 Pavia, Italy

M. Rondanelli · V. Infantino

Department of Public Health, Experimental and Forensic Medicine, Unit of Human and Clinical Nutrition, University of Pavia, 27100 Pavia, Italy

M. A. Faliva · A. Tartara · C. Gasparri $(\bowtie) \cdot$ G. Peroni Endocrinology and Nutrition Unit, Azienda Di Servizi Alla Persona "Istituto Santa Margherita", University of Pavia, 27100 Pavia, Italy

e-mail: clara.gasparri01@universitadipavia.it

G. Peroni

e-mail: gabriella.peroni01@universitadipavia.it

S. Perna

Department of Biology, College of Science, University of Bahrain, 32038 Sakhir, Bahrain

A. Riva · G. Petrangolini

Research and Development Unit, Indena,

Milan, Italy been considered since 1990, because it is not included in the EFSA claims) and bone health in humans. This review included 28 eligible studies: nine studies concern Mg blood, 12 studies concern $\mathrm{Mg}$ intake and seven studies concern $\mathrm{Mg}$ supplementation, alone or in combination with other nutrients. From the various studies carried out on the serum concentration of $\mathrm{Mg}$ and its relationship with the bone, it has been shown that lower values are related to the presence of osteoporosis, and that about $30-40 \%$ of the subjects analyzed (mainly menopausal women) have hypomagnesaemia. Various dietetic investigations have shown that many people (about 20\%) constantly consume lower quantities of $\mathrm{Mg}$ than recommended; moreover, in this category, a lower bone mineral density and a higher fracturing risk have been found. Considering the intervention studies published to date on supplementation with $\mathrm{Mg}$, most have used this mineral in the form of citrate, carbonate or oxide, with a dosage varying between 250 and $1800 \mathrm{mg}$. In all studies there was a benefit both in terms of bone mineral density and fracture risk.

Keywords Magnesium · Bone - Dietary supplementation $\cdot$ Bone mineral density $\cdot$ Nutrients 


\section{Introduction}

Magnesium $(\mathrm{Mg})$ is an intracellular cation (second in abundance after potassium), ubiquitous in the human body where it is present (adult organism) in quantities of about 20-28 g: $60 \%$ is found in the bones, $39 \%$ in the intracellular compartments and about $1 \%$ in the extracellular liquids. $\mathrm{Mg}$ is present in almost all foods in varying concentrations. It is contained in leaf vegetables in a concentration of $30-60 \mathrm{mg} / 100 \mathrm{~g}$, being in the center of the pyrrolic core of chlorophyll. Larger quantities are contained in legumes (80-170 mg/100 g), nuts (130-264 mg/100 g) and whole grains (up to $550 \mathrm{mg} / 100 \mathrm{~g}$ in wheat bran). More than $80 \%$ of the $\mathrm{Mg}$ is removed from the grain refining treatments (white bread contains only $15 \mathrm{mg}$ / $100 \mathrm{~g})$. High quantities are present in the coffee (80 mg/100 $\mathrm{g}$ in the ready-to-drink) (US Department of Agriculture 2009). Dried fruit in general, potatoes and food of animal origin (meat, fish, milk and derivatives) are less rich in $\mathrm{Mg}(20-70 \mathrm{mg} / 100 \mathrm{~g})$ (Carnovale and Marletta 2013). The concentration of $\mathrm{Mg}$ in the water is highly variable depending on its origin. The labels of the 150 bottled waters consumed in the scope of the INRAN-SCAI 2005-06 survey (Leclercq et al. 2009) show that the content varies from 1 to $109 \mathrm{mg} / \mathrm{L}$, with an average of $15 \mathrm{mg} / \mathrm{L}$. The bioavailability of $\mathrm{Mg}$ varies in the presence of specific components of the diet: phytates, calcium, phosphorus and long chain fatty acids decrease its absorption, while there are conflicting evidences about the effect of oxalic acid.

So, the potential benefits of consuming magnesium might be masked with the effects of other nutrients.

Cooking food also reduces its bioavailability (Dilworth et al. 2007), which instead increases in the presence, for example, of proteins, fructose, inulin, fruit- and galact-oligosaccharides (Roth and Werner 1979; Seelig 1981; Lönnerdal 1997; Coudray et al. 2003, 2005).

The recommended intake levels (RDA) of $\mathrm{Mg}$ were provided by the United States Food and Nutrition Board (Food and Nutrition Board 1997).

Several dietary surveys conducted in the United States show that many people consume less than the recommended amounts of $\mathrm{Mg}$ constantly. A 2013-2016 National Health and Nutrition Examination Survey (NHANES) data analysis found that $48 \%$ of Americans of all ages take less $\mathrm{Mg}$ from food and drink than their average needs; adult men 71 years of age and older, teenagers are more likely to show low Mg intake (US Department of Agriculture 2019).

So the dietary intake of $\mathrm{Mg}$ is on average insufficient, but clinical diagnosis of $\mathrm{Mg}$ deficiency is not simple, as symptoms associated with $\mathrm{Mg}$ deficiency are unspecific, and generally confounded by low consumption of other nutrients.

Unfortunately, routinely measured serum Mg levels do not always reflect total body $\mathrm{Mg}$ status, so normal level of serum $\mathrm{Mg}$ does not rule out moderate to severe Mg deficiency (Razzaque 2018).

In 2009, EFSA issued an opinion on health claims related to $\mathrm{Mg}$ with the diet, establishing that there is sufficient scientific evidence to indicate that dietary $\mathrm{Mg}$ contributes to various functions of the body, including electrolyte balance, the energy performance of the metabolism, neurotransmission and muscle contraction, including heart muscle, cell division, protein synthesis and finally the maintenance of bones and teeth (European Food Safety Authority 2009).

In particular, considering bone health, $\mathrm{Mg}$ has a pivotal role.

$\mathrm{Mg}$ deficiency might affect bone directly (by reducing bone stiffness, increasing osteoclasts and decreasing osteoblasts) and indirectly (by interfering with PTH and vit D, promoting inflammation/oxidative stress and subsequent bone loss) (Castiglioni et al. 2013).

$\mathrm{Mg}$ is an essential cofactor for vitamin D synthesis and activation and, in turn, can increase intestinal absorption of $\mathrm{Mg}$ and establish a feed-forward loop to maintain its homeostasis (Uwitonze and Razzaque 2018; Erem et al. 2019).

Given this background, the aim of this narrative review was to consider the state of the art since 2009 on relationship between $\mathrm{Mg}$ blood levels, magnesium dietary intake and $\mathrm{Mg}$ dietary supplementation (alone or with other micronutrients; this last topic has been considered since 1990, because it is not included in the EFSA claims) and bone health in humans.

\section{Materials and methods}

The present narrative review was performed following the steps by (Egger et al. 2008) as follows: 
(1) Configuration of a working group: three operators skilled in clinical nutrition (one acting as a methodological operator and two participating as clinical operators).

(2) Formulation of the revision question on the basis of considerations made in the abstract: "the state of the art since 2009 on the correlation between human blood Mg concentrations, daily $\mathrm{Mg}$ intake with food and bone mineral density and since 1990 on the correlation between $\mathrm{Mg}$ dietary supplementation and bone mineral density.

(3) Identification of relevant studies: a research strategy was planned on PubMed (Public MedIine run by the National Center of Biotechnology Information (NCBI) of the National Library of Medicine of Bethesda (USA)) as follows: (a) Definition of the keywords (magnesium, bone health, humans, intake, supplementation, bone mineral density), allowing the definition of the interest field of the documents to be searched, grouped in quotation marks (“...") and used separately or in combination; (b) use of: the Boolean (a data type with only two possible values: true or false) AND operator, that allows the establishments of logical relations among concepts; (c) Research modalities: advanced search; (d) Limits: time limits: papers published since 2009 for the evaluation of correlation between human blood $\mathrm{Mg}$ concentrations, daily dietary $\mathrm{Mg}$ intake and bone mineral density and since 1990 for the evaluation of the correlation between $\mathrm{Mg}$ dietary supplementation and bone mineral density; humans; adults; languages: English; (e) Manual search performed by the senior researchers experienced in clinical nutrition through the revision of articles on the state of the art on the correlation between human blood magnesium concentrations, daily magnesium intake with food, magnesium supplementation and bone mineral density.

(4) Published in journals qualified in the Index Medicus.

(5) Analysis and presentation of the outcomes: we create paragraphs about the state of the art on the correlation between human blood Mg concentrations, daily $\mathrm{Mg}$ intake with food, Mg supplementation and bone mineral density, and the data extrapolated from the "revised studies" were collocated in tables; in particular, for each study we specified the author and year of publication and study characteristics.

(6) The analysis was carried out in the form of a narrative review of the reports. At the beginning of each section, the keywords considered and the type of studies chosen are reported. We evaluated, as is suitable for the narrative review, studies of any design which considered the state of the art on the correlation between human blood Mg concentrations, daily Mg intake with food, $\mathrm{Mg}$ supplementation and bone mineral density.

Figure 1 shows the flow chart of literature research.

\section{Results}

Serum magnesium concentration and effects on bone metabolism

This research was conducted based on the keywords: "blood magnesium" AND "bone" AND "humans".

For the present review we have analyzed a total of nine studies: four observational studies, two casecontrol studies, one cross-sectional study, one longitudinal cohort study and one prospective cohort study.

The results of these seven studies have been shown in Table 1.

\section{Magnesemia and bone mineral density}

With regard to the serum concentration of $\mathrm{Mg}$, most of the studies has focused on postmenopausal women. In this regard, Mederle et al. conducted a study in 2018 to investigate the correlation between bone mineral density (BMD) and serum Mg levels in 132 postmenopausal osteoporotic women compared with 81 healthy (non-osteoporotic) women, always in postmenopause. Osteoporotic women showed significantly lower concentrations of serum $\mathrm{Mg}$ compared to the control group $(1.76 \pm 0.06 \mathrm{mg} / \mathrm{dl}$ compared to $2.14 \pm 0.14 \mathrm{mg} / \mathrm{dl})$, while remaining in the reference range (1.6-2.4 mg/dl), moreover i $\mathrm{Mg}$ levels were positively correlated with BMD values (Mederle et al. 2018). Another study on postmenopausal women is that carried out by Okyay et al. in 2013, in which the 


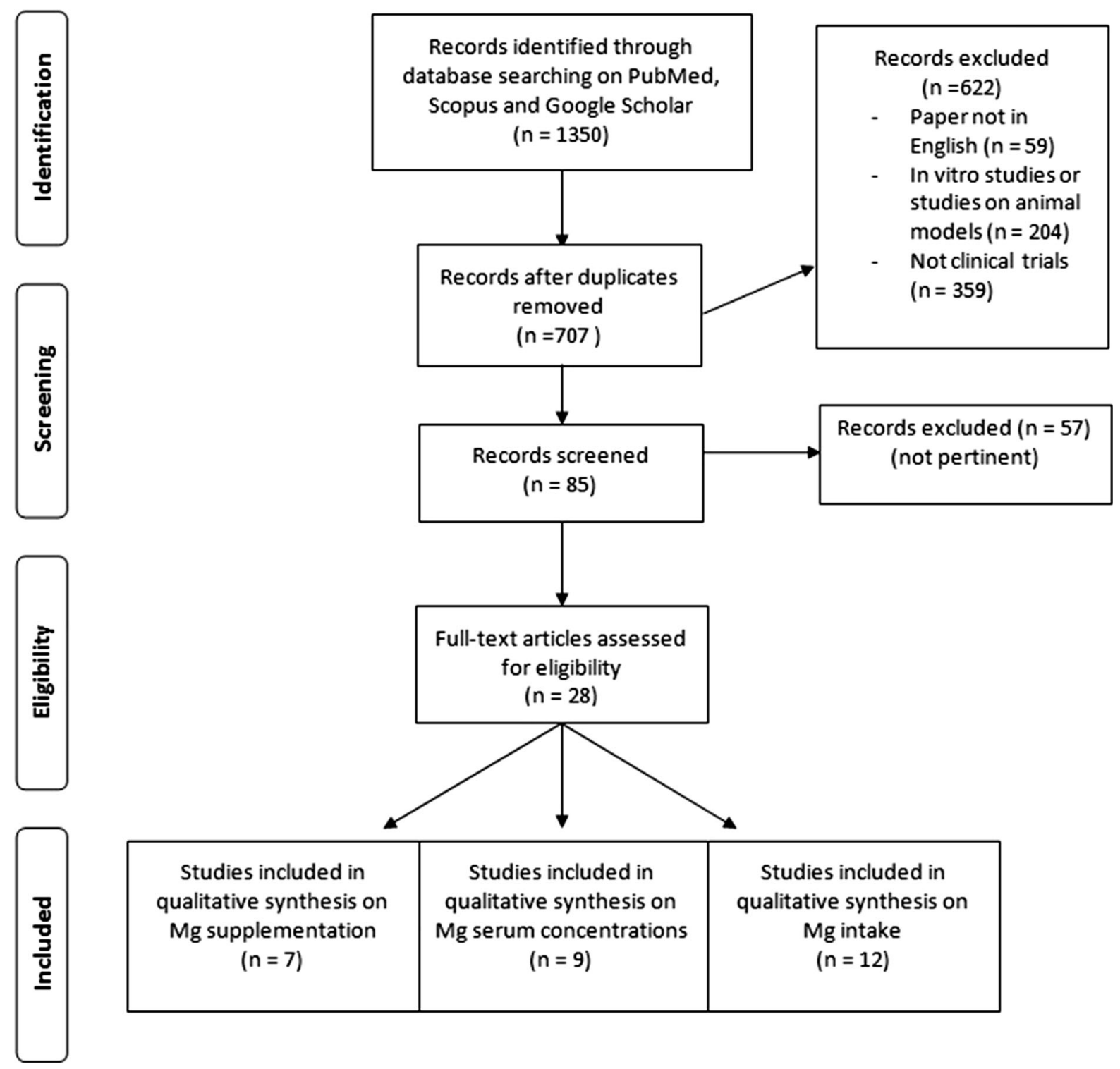

Fig. 1 Flow chart of literature research

relationship between the serum concentrations of different minerals was assessed, including $\mathrm{Mg}$ and the presence of osteoporosis. The 728 women enrolled were then divided into 2 groups, according to the presence or absence of osteoporosis, and the results of the analysis carried out found a significant association between low serum Magnesium $(\mathrm{Mg})$ values and the presence of both lumbar (L1-L4) and osteoporosis femoral. In this study it was also highlighted that, between 45 and 59 years, $47.1 \%$ of osteoporotic women at the level of L1-L4, 29.4\% of osteoporotic women at the level of the whole femur and 32., $4 \%$ of osteoporotic women at the neck of the femur have a serum $\mathrm{Mg}$ value lower than the reference range (Okyay et al. 2013). Moreover, the group of Mahdavi et al. wanted to examine the serum concentration of $\mathrm{Mg}$, Zinc, Copper and Calcium in 51 women: 23 osteoporotic and 28 osteopenic. Specifically, for $\mathrm{Mg}$ it was shown that $40.4 \%$ of women had a lower serum concentration than the reference ranges, without statistically significant differences between the 2 groups (Mahdavi-Roshan et al. 2015). Other analysis 


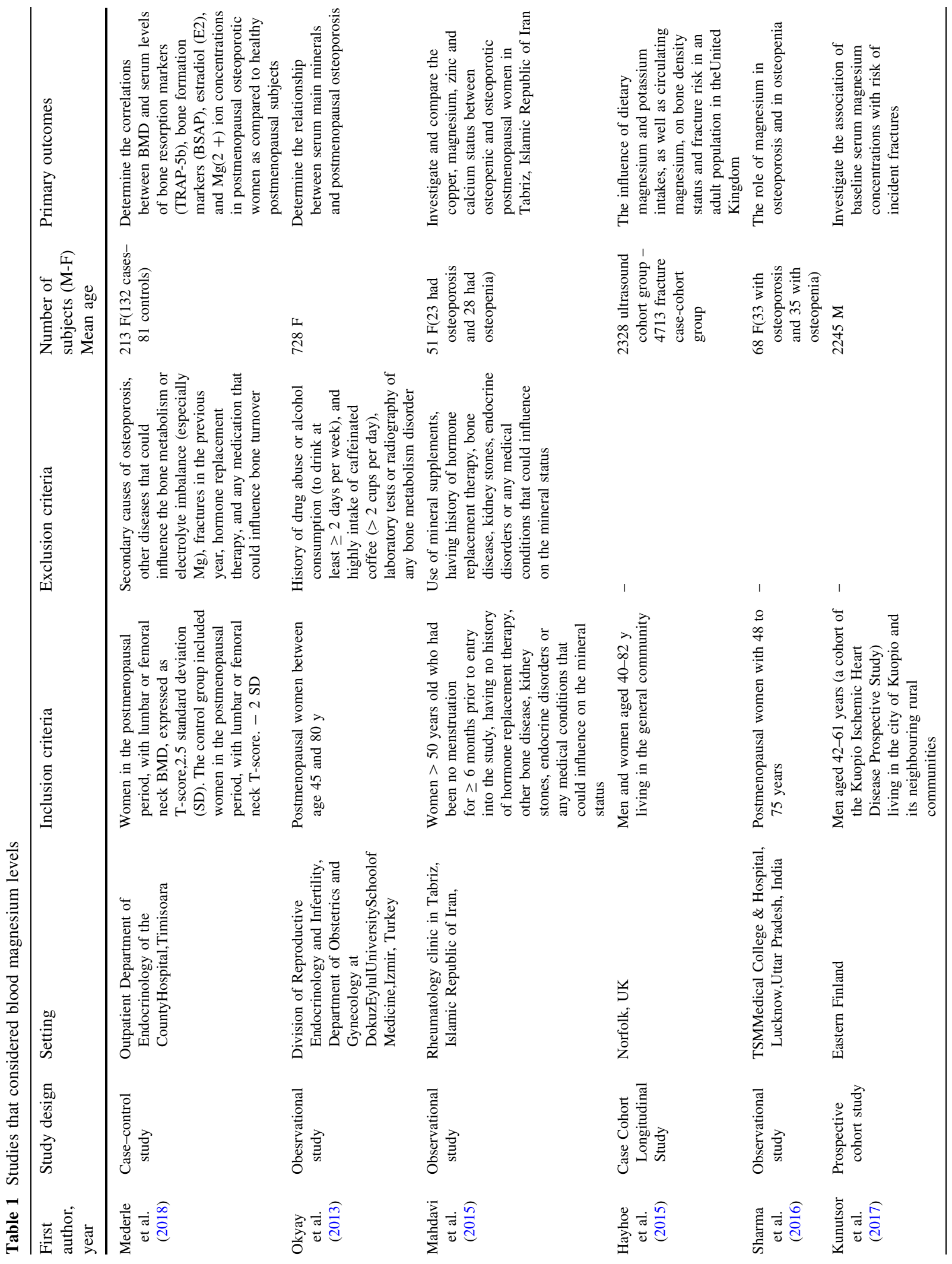




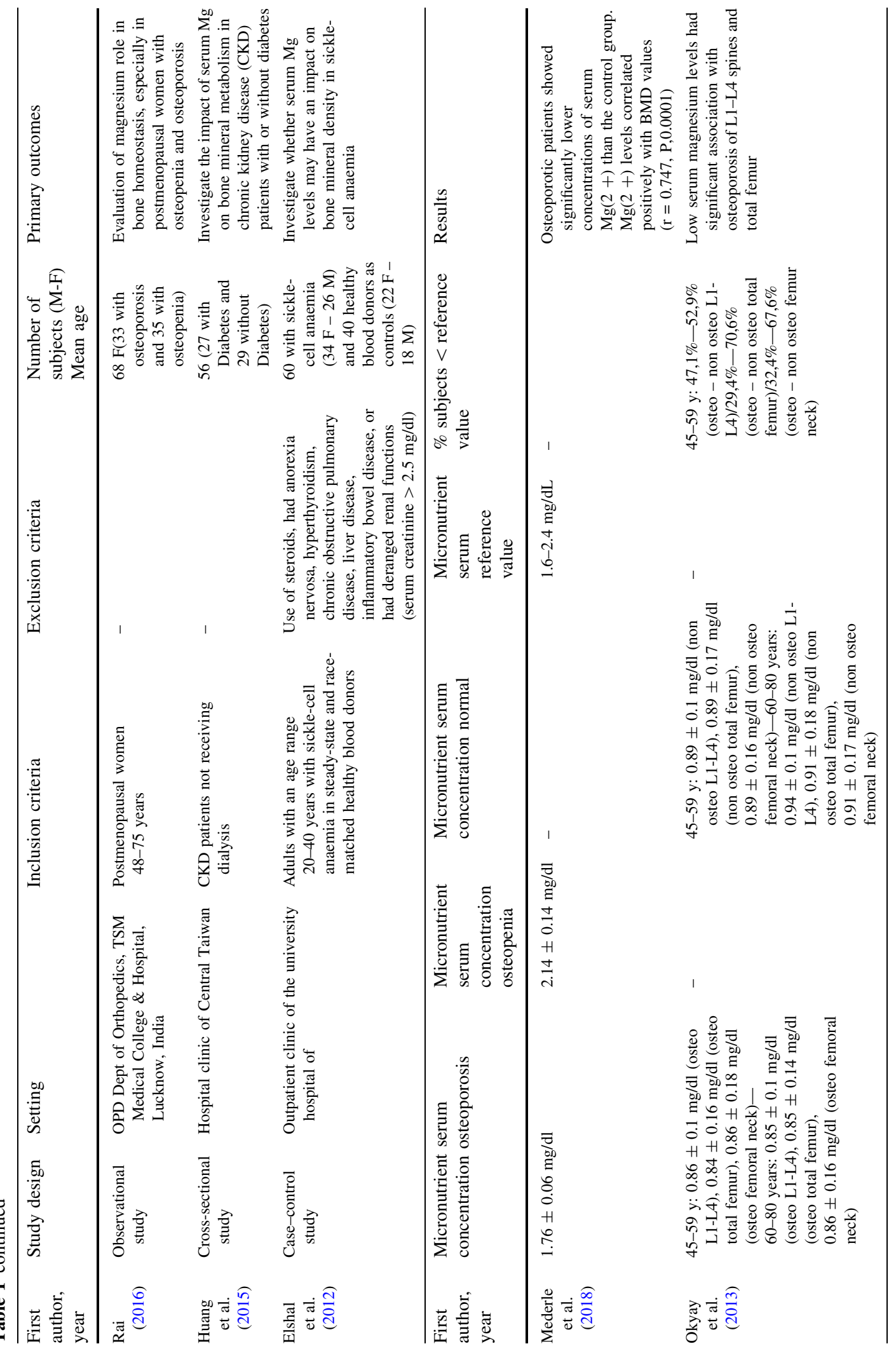


Biometals (2021) 34:715-736

721

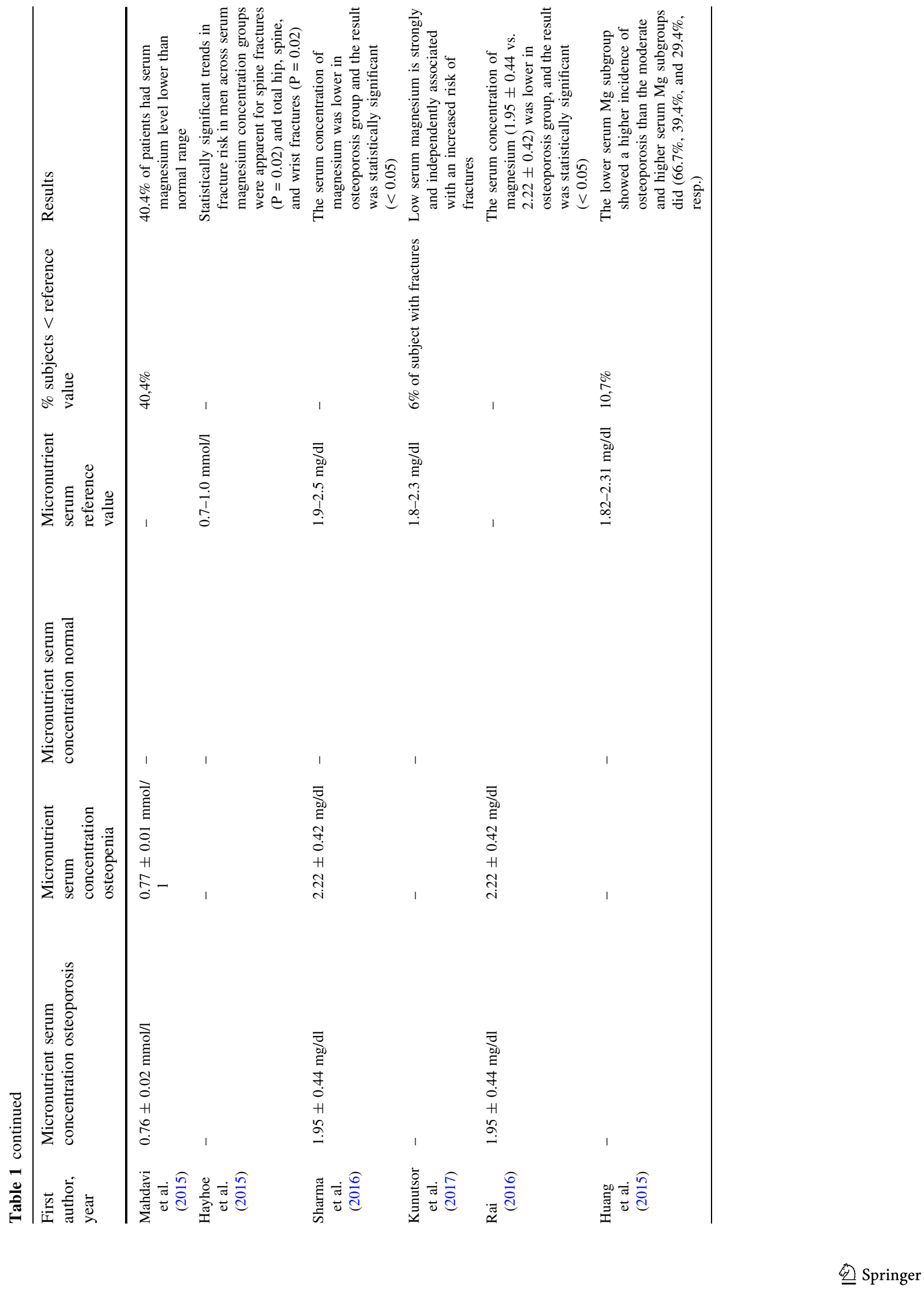




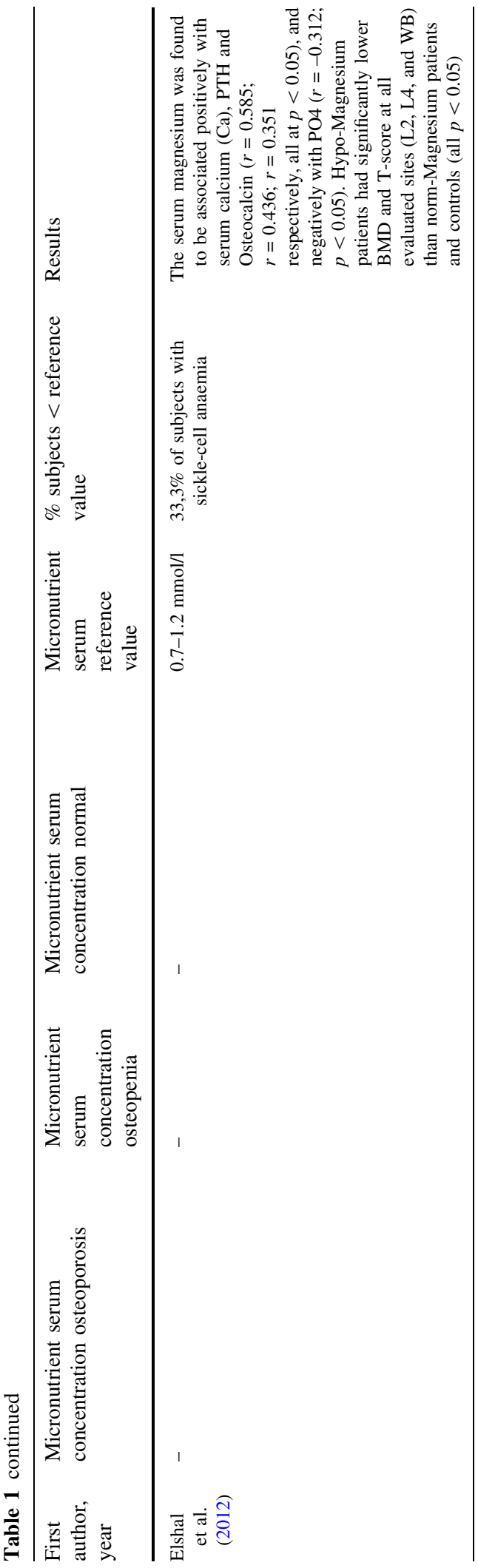

on the relationship between serum $\mathrm{Mg}$ concentration and the presence of osteopenia and osteoporosis have been carried out: a study carried out in India has observed that serum $\mathrm{Mg}$ in women with osteoporosis $(1.95 \pm 0.44 \mathrm{mg} / \mathrm{dl})$ was significantly lower than to women with osteopenia $(2.22 \pm 0.42 \mathrm{mg} / \mathrm{dl})$, however remaining within the reference ranges (1.9-2.5 mg/dl) (Sharma et al. 2016). Also in India, a further study on 68 women, including 33 osteoporotic and 35 with osteopenia, observed that the serum $\mathrm{Mg}$ concentration was lower in the osteoporosis group $(1.95 \pm 0.44 \mathrm{mg} / \mathrm{dl})$ compared with osteopenic women $(2.22 \pm 0.42 \mathrm{mg} / \mathrm{dl})$ in a statistically significant way (Rai and Sharma 2016).

\section{Magnesiemia and fracturing risk}

Moreover, it is important to evaluate the role of $\mathrm{Mg}$ in fracture risk, both in women and men. In this regard, a UK cohort study, analyzing subjects of both sexes belonging to the EPIC-Norfolk study, investigated the influence of serum $\mathrm{Mg}$ on bone density, assessed by means of a bone analyzer ultrasound, and fracture risk. The analysis showed statistically significant trends in the risk of fracture in men, especially for spinal $(\mathrm{P}=0.02)$, hip and wrist fractures $(\mathrm{P}=0.02)$ (Hayhoe et al. 2015).

Another cohort study carried out in Finland, analyzing subjects from the KIHD study, wanted to study the association of serum magnesium concentrations with the risk of fractures in adult subjects of both sexes. Considering a reference range of $1.8-2.3 \mathrm{mg} / \mathrm{dl}$, $6 \%$ of subjects with fractures were found to have a lower serum $\mathrm{Mg}$ value; moreover, the Mg concentration was strongly associated with a high risk of fractures (Kunutsor et al. 2017).

In addition to "healthy" subjects, it can be useful to evaluate the $\mathrm{Mg}$ values in the blood also in subjects with pathologies that in some way can interfere with a normal bone turnover. Chronic kidney disease causes progressive renal function decline over time. Serum $\mathrm{Mg}$ levels may increase with renal functional decline (Navarro-González et al. 2009) and this may possibly be harmful to bone health (Castiglioni et al. 2013). Huang and colleagues, analyzing 56 patients with chronic kidney disease, not yet on dialysis, found that $10.6 \%$ of the subjects had a serum $\mathrm{Mg}$ value lower than the reference range $(1.82-2.31 \mathrm{mg} / \mathrm{dl}$ ) (Huang et al. 2015). The different pathological conditions of 
the bone, including osteopenia and osteoporosis, are also a frequent cause of morbidity in sickle cell anemia. $\mathrm{Mg}$ regulates some important biological processes in bone remodeling and participates in the pathophysiology of erythrocyte sickle. 60 adult subjects-with an age range from 20 to 40 years-with sickle cell anemia were analyzed by evaluating their serum $\mathrm{Mg}$ concentration: $33.3 \%$ were found to be deficient. Furthermore, there was a positive association between serum $\mathrm{Mg}$, calcium, parathyroid hormone and osteocalcin, and subjects with hypomagnesaemia were found to have a lower bone mineral density, both lumbar and whole body, compared to subjects with normal serum values (Elshal et al. 2012).

In conclusion, all studies published since 2009 agree in confirming that subjects with hypomagnesaemia were found to have a lower bone mineral density.

Dietary intake of magnesium and effects on bone metabolism

This research was conducted based on the keywords: "dietary magnesium intake" AND "bone" AND "humans". It have been considered studies since 2009.

For the present review we have analyzed a total of 12 studies: five prospective studies, two cross-sectional studies, one longitudinal cohort study, two prospective cohort studies, one observational study and one cross-sectional cohort study.

The results of these seven studies have been shown in Table 2.

For human studies, the investigations on food intake were carried out mostly thanks to the use of questionnaires (Food Frequency Questionnaire mainly) and the subjects analyzed were mainly preor post-menopausal women. A recent evaluation of a cohort of 144 postmenopausal black women from the PURE-SA-NWP study (Teo et al. 2009) analyzed the association between intake and dietary patterns with changes in bone turnover and bone mineral density. $\mathrm{Mg}$ intake was lower than the estimated average requirement $(265 \mathrm{mg} /$ day) for $21.1 \%$ of women and statistically correlated negatively with type I collagen C-Telopeptide, a specific marker of bone resorption (Wright et al. 2019). Furthermore, the bone mineral density of the hip and the whole body were significantly higher, respectively by $3 \%$ and $2 \%$, in women who with intake $>422.5 \mathrm{mg}$ /day compared to intake of $\mathrm{Mg}<206.5 \mathrm{mg} / \mathrm{day}$ (Orchard et al. 2014). The positive association between bone mineral density and $\mathrm{Mg}$ intake was also found in another analysis conducted on 142 post-menopausal women: in addition to this data, it was also possible to observe the positive association, statistically significant, between $\mathrm{Mg}$ and Propeptide type I Procollagen, a marker of collagen formation during bone formation (Gunn et al. 2014). In addition to the questionnaires already mentioned, there are also various methods of evaluating the food intake; the most widely used is certainly that of the food diary, which consists in recording the food taken for 3 consecutive days, one of which at the weekend. 244 post-menopausal women used both this method and the Food Frequency Questionnaire, to compare the intake in relation to their bone mineral density: in this case, in addition to $\mathrm{Mg}$, also Iron was found to be positively associated with bone density regardless of the dietary assessment method used (Farrell et al. 2009). Regarding the recommended daily dose of $\mathrm{Mg}$, Mahdavi and collaborators have found that, in post-menopausal osteoporotic and osteopenic women, the average dietary intake of $\mathrm{Mg}$, Zinc and Calcium was significantly lower, confirming again once the relationship between these minerals and good bone maintenance (Mahdavi-Roshan et al. 2015).

As with the serum concentration, also in men it is important to evaluate the $\mathrm{Mg}$ intake and its relationship with bone density. A study analysis aimed to evaluate 3765 subjects of both sexes, enrolled in the Osteoarthritis Initiative (OAI) database of 4 American states, considering the association between their $\mathrm{Mg}$ intake and fracturing risk: men and women resulting in the quintile of intake higher $(>398 \mathrm{mg} /$ day men and $>373 \mathrm{mg} /$ day women) reported a significantly lower risk of fracture; in addition, women with an intake equivalent to the recommended dose of $\mathrm{Mg}$ found a $27 \%$ reduced risk of future fractures. Despite this, the intake of $19.9 \%$ of women and $20 \%$ of men was lower than the lowest quintile $(<205 \mathrm{mg} /$ day men and $<190 \mathrm{mg} /$ day women), and therefore with a greater risk of developing fractures or to reduce bone density (Veronese et al. 2017). With reference to the intake quintiles, similar results were also found in the UK population, in an analysis that involved subjects of both sexes with a fairly wide age range (37-73 years): specifically the intake of $\mathrm{Mg}$ and $19.9 \%$ of women and 


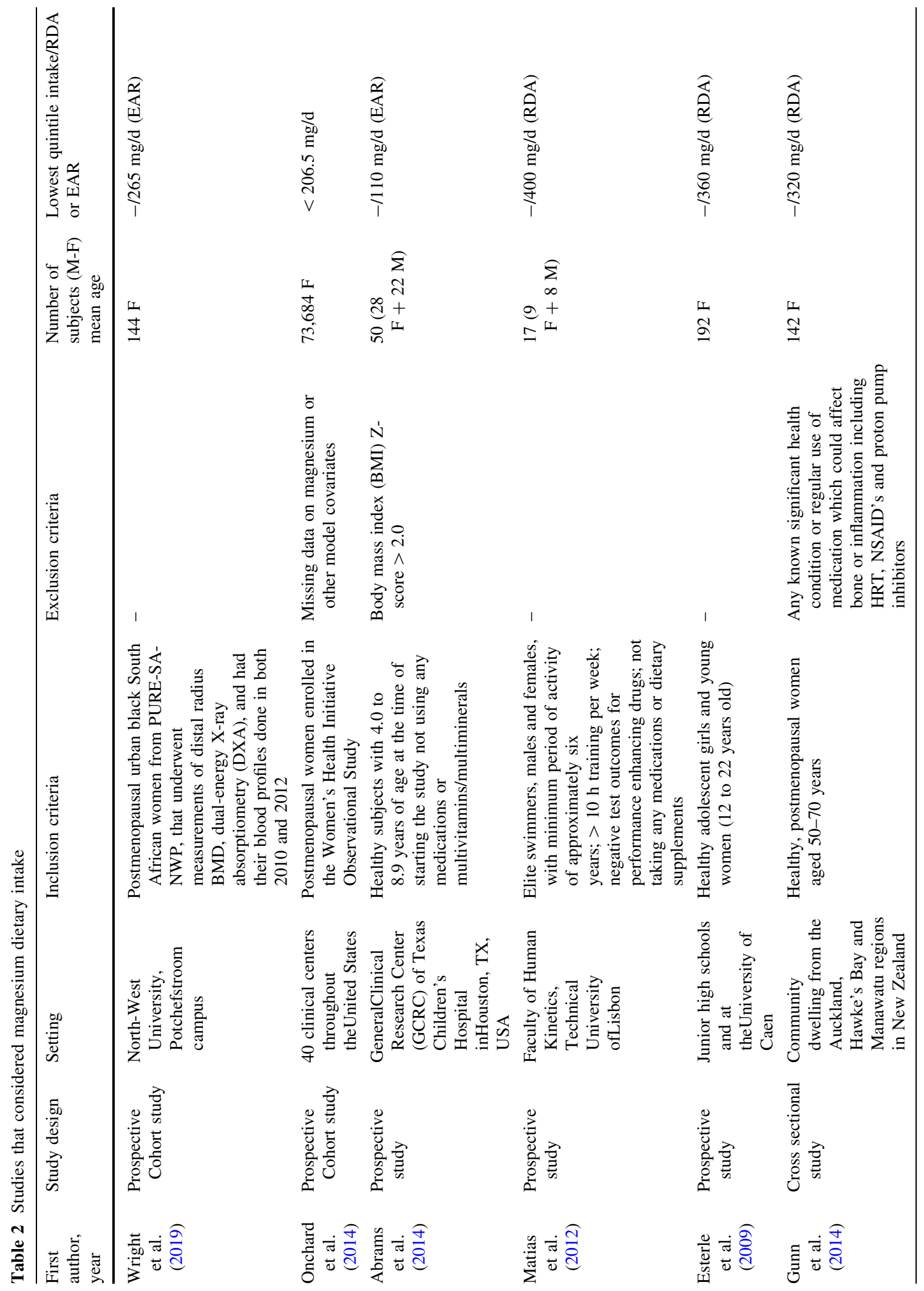




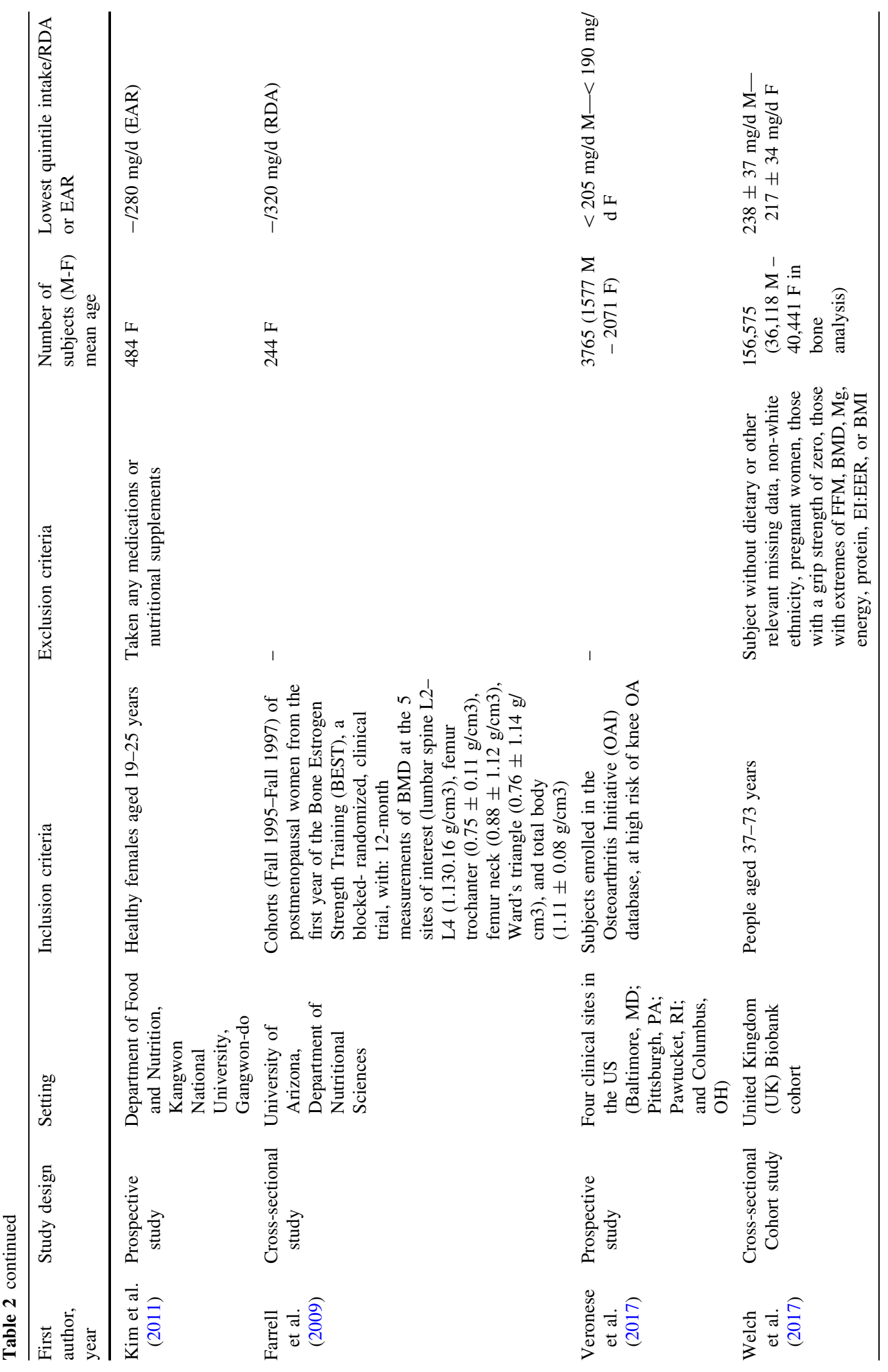




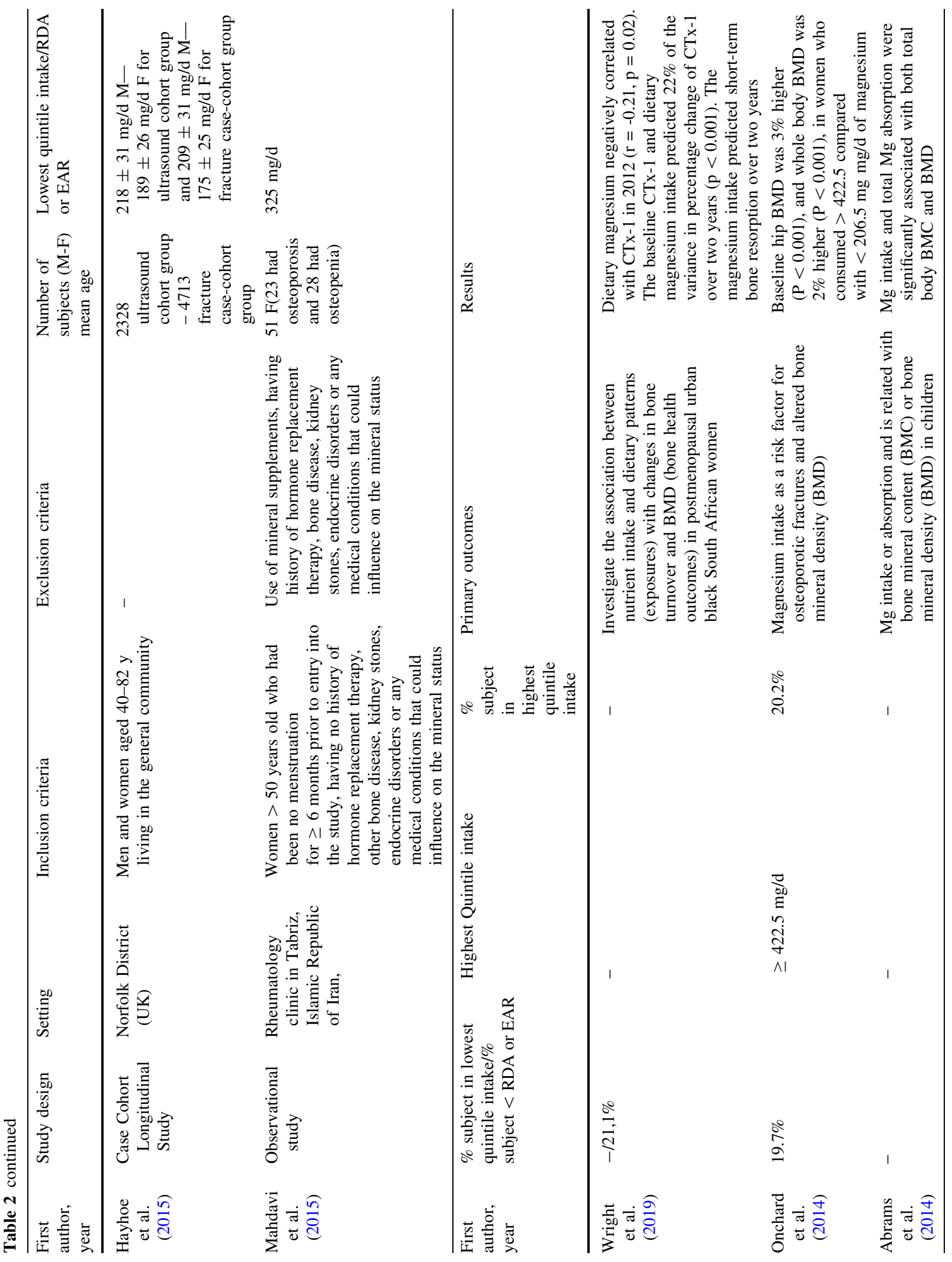




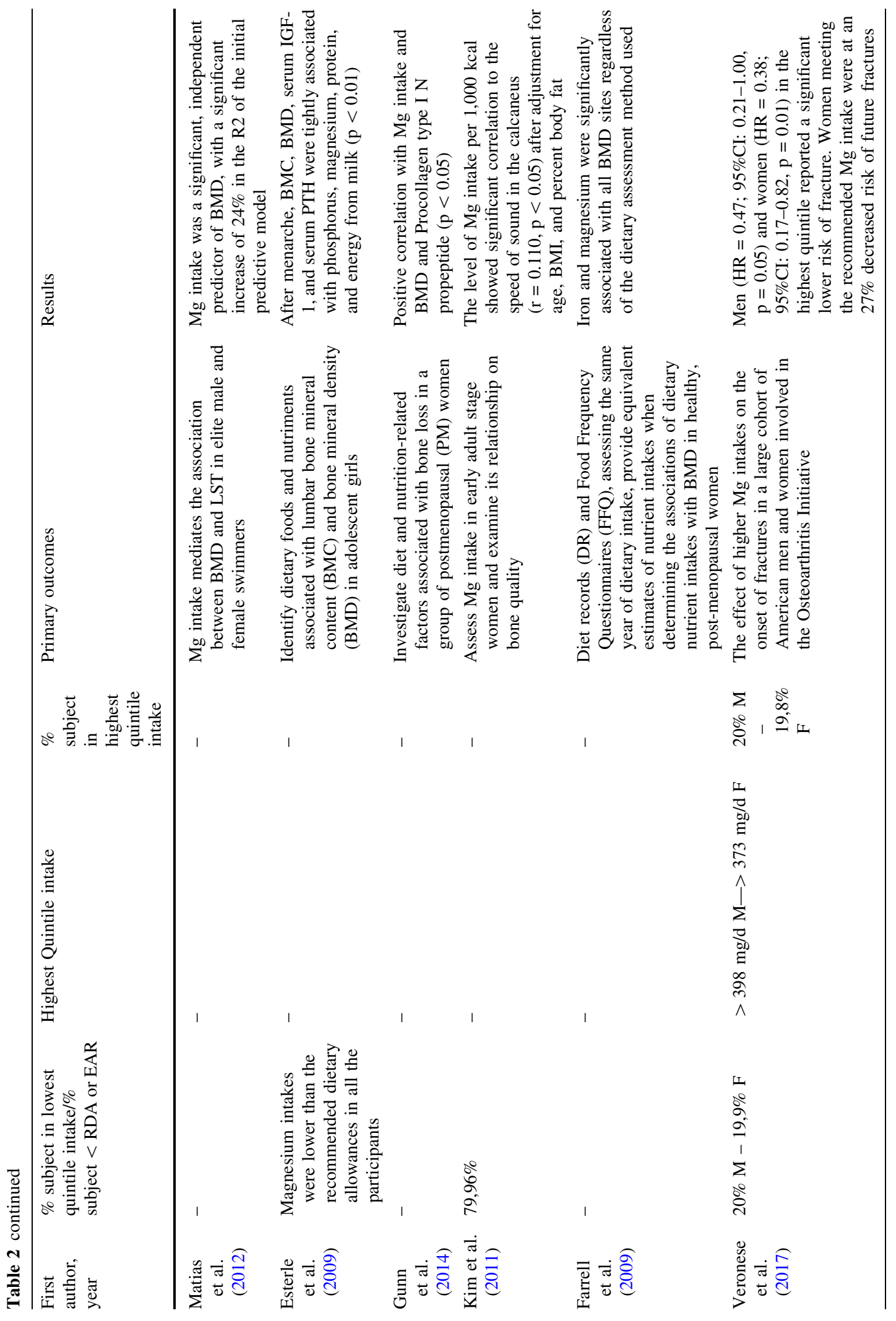




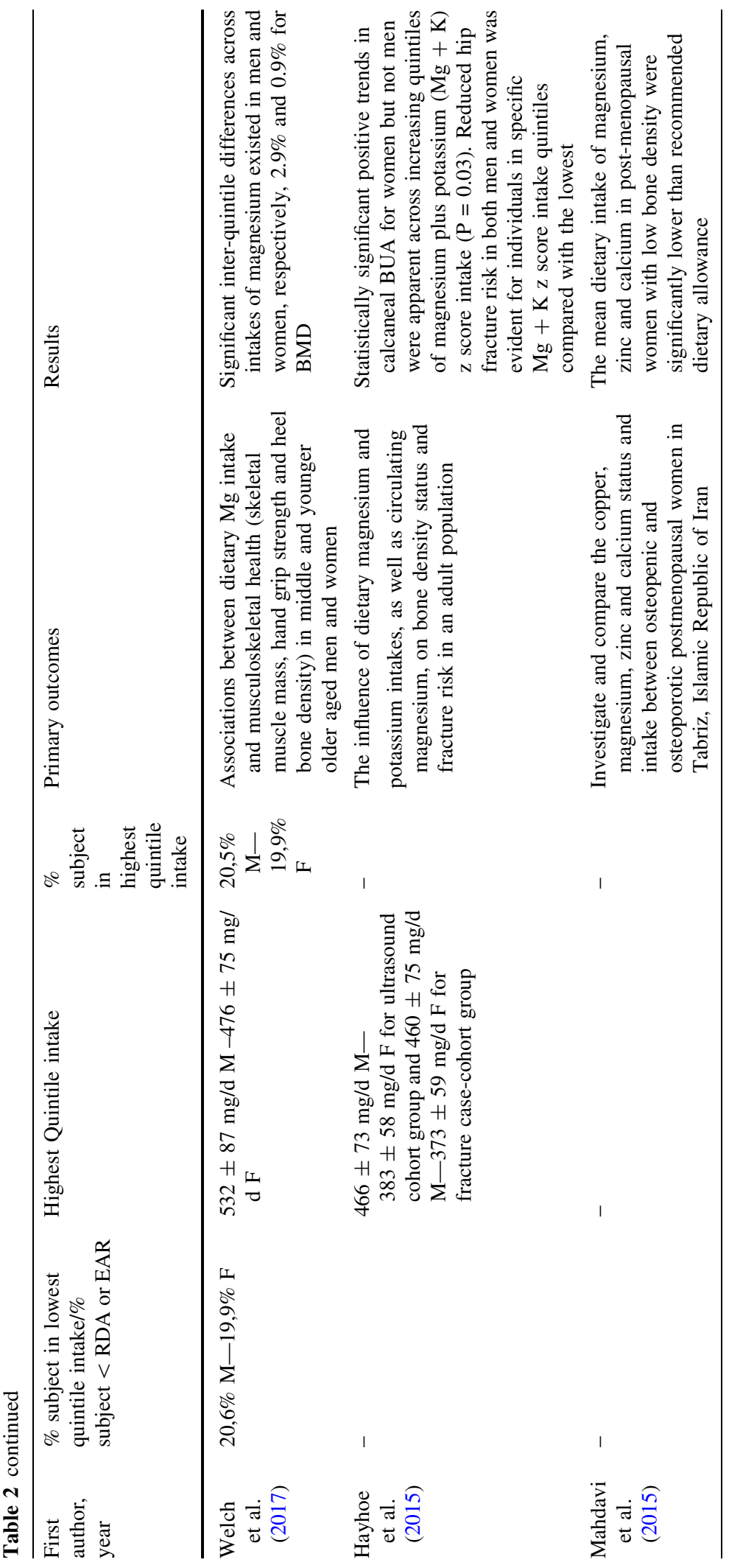


$20.6 \%$ of men were lower than the lowest quintile $(238 \pm 37 \mathrm{mg} /$ day men and $217 \pm 34 \mathrm{mg} /$ day women). In addition to this, significant differences were also found between the quintiles of $\mathrm{Mg}$ for bone mineral density, in men and women, of $2.9 \%$ and $0.9 \%$ respectively, thus further confirming the relationship between $\mathrm{Mg}$ and bone (Welch et al. 2017). Regarding fractures, a UK cohort study, analyzing subjects of both sexes belonging to the EPIC-Norfolk study, investigated the influence of $\mathrm{Mg}$ and Potassium intake on bone density, evaluated using an ultrasound bone analyzer and fracture risk. In this regard, positive, statistically significant trends in attenuation of calcaneal broadband ultrasound for women, but not for men, have been highlighted, through the increase in $\mathrm{Mg}+$ potassium quintiles. The reduced risk of hip fracture, both in men and in women, was instead shown in higher quintiles of $\mathrm{Mg}+$ Potassium than the lowest (Hayhoe et al. 2015).

A correct assessment of the $\mathrm{Mg}$ intake in relation to bone is important to implement also in young subjects, such as children or adolescents. A study conducted on 192 teenage girls from the University of Caen, France, showed that their $\mathrm{Mg}$ intake was lower than the recommended daily dose $(360 \mathrm{mg} /$ day $)$, also observing that, after menarche, bone mineral density and the parathyroid hormone is closely associated with the intake of $\mathrm{Mg}$, Phosphorus and milk proteins (Esterle et al. 2009). The relationship between $\mathrm{Mg}$ intake and correct bone development was also investigated in North Korean adolescents: out of 484 girls analyzed, the intake of $79.96 \%$ of the sample was lower than the recommended average requirement $(280 \mathrm{mg} /$ day $)$. Furthermore, the intake level of $\mathrm{Mg}$ per 1,000 kcal showed a significant correlation with the speed of sound in the heel, detected by the instrument used for bone mineral density (Kim et al. 2011).

Male adolescents were also subjected to several analyses. Abrams and collaborators investigated the intake of $\mathrm{Mg}$ and its relationship with bone mineral density and bone mineral content on adolescents/ children of both sexes: the intake of $\mathrm{Mg}$ and its absorption were significantly associated with both density and mineral content (Abrams et al. 2014). The mother's diet during pregnancy is also an important factor to consider in order to better evaluate the baby's bone mineral density.

Physical activity is also fundamental for bone mineralization, in addition, the loss of bone mass was accelerated in subjects with low $\mathrm{Mg}$ intake. In this regard, a study carried out in Portugal has evaluated whether, in 17 elite swimmers of both sexes, the $\mathrm{Mg}$ intake could have an association with bone mineral density; to reinforce this thesis, the intake of $\mathrm{Mg}$ was actually a significant predictor of both bone density and lean tissue, thus confirming that young athletes engaged in low-impact sports should pay particular attention to the intake of $\mathrm{Mg}$, given its potential role in the acquisition of bone mineral mass during growth (Matias et al. 2012).

In conclusion, various dietetic investigations performed since 2009 have shown that many people (about 20\%) constantly consume lower quantities of $\mathrm{Mg}$ than recommended; moreover, in this category, a lower bone mineral density and a higher fracturing risk have been found. These results have been demonstrated in both the elderly and young people.

Magnesium dietary supplements alone or in combination with other nutrients

This research was conducted based on the keywords: “ magnesium supplementation" AND "bone" AND "humans". It have been considered studies since 1990.

For the present review we have analyzed a total of 7 studies: 3 case-control studies, 1 retrospective study, 1 randomized controlled trial, 1 prospective, placebocontrolled randomized double blind trial and 1 double blind, placebo-controlled trial.

The results of these seven studies have been shown in Table 3.

The effect of $\mathrm{Mg}$ supplementation on bone mass has not been extensively studied. New research is therefore being developed in order to evaluate the effects of different nutritional supplements on bone health, both in subjects with osteoporosis and in "healthy" subjects.

The studies relating to the supplementation of $\mathrm{Mg}$ for the bone mainly concern postmenopausal women. A randomized controlled clinical trial sought to analyze the short-term effects of daily oral supplementation of $\mathrm{Mg}$ on biochemical markers of bone turnover in 20 post-menopausal osteoporotic women. Divided into 2 groups, 10 women received a treatment for 30 days, which consisted of a daily oral dose of $1,830 \mathrm{mg}$ of magnesium citrate in the form of magnesium tablets, while the other 10 , not receiving any supplementation, were considered as controls. In 
the $\mathrm{Mg}$ supplemented group, a significant reduction in serum parathyroid hormone levels was observed; a significant increase in serum osteocalcin levels and a significant decrease in urinary deoxypyridinoline levels (Aydin et al. 2010). Mg supplementation in osteoporotic postmenopausal women was also evaluated in relation to trabecular bone density: 54 women therefore participated in an Israeli case-control study, lasting 2 years. 31 women at the beginning of the study received two $\mathrm{Mg}$ tablets $(250 \mathrm{mg}$ of $\mathrm{Mg}$ ); the dosage was then increased based on individual tolerance levels, to reach a maximum of two tablets three times a day (750 $\mathrm{mg}$ of $\mathrm{Mg}$ ). The maximum dose was administered for 6 months, followed by a maintenance dose of two tablets once a day ( $250 \mathrm{mg}$ of magnesium) for an additional 18 months. 23 postmenopausal women with symptom-free osteoporosis who refused treatment were instead analyzed as controls. The average bone density of treated women increased significantly after one year and after 2 years, while the average bone density decreased significantly in untreated women. $\mathrm{Mg}$ therapy prevented fractures and resulted in a significant increase in bone density in $71 \%$ of women and stopping bone loss in $16 \%$ (Stendig-Lindberg et al. 1993). This increase in bone density was also found in another study, in which 53 osteoporotic women, divided according to the intake of Silicon (8 women), Fluoride (10 women), Etidronate (13 women) and $\mathrm{Mg}$ (6) supplements women), were compared with 16 women without treatment, for a period of 14-22 months. It was therefore possible to observe how $\mathrm{Mg}$ induced a slight but statistically insignificant increase in vertebral bone mineral density (Eisinger and Clairet 1993).

$\mathrm{Mg}$ supplementation in menopausal women has also proved more effective in a combination with other minerals. In this regard, a study analyzed the effect on mineral density of the calcaneus bone in postmenopausal women, with hormone replacement therapy in place, of a supplement of $\mathrm{Mg}$ and Calcium for 6-12 months. 26 women were then divided into 2 groups: one, consisting of 19 women, with the intake of a complete supplement containing $500 \mathrm{mg}$ of calcium as citrate salt and $200 \mathrm{mg}$ of $\mathrm{Mg}$ as oxide, with a dosage of $6 \mathrm{cp} /$ day, the other, with 7 women, followed with dietary advice but who have not chosen to take the supplement. An insignificant increase-of $0.7 \%$-in the average bone mineral density of the 7 women who underwent dietary advice was observed while in the 19 women who took the supplements an average increase of $11 \%$ was observed (Abraham and Grewal 1990).

Therefore confirmed the importance of $\mathrm{Mg}$ supplementation in menopausal women, it is useful to investigate how $\mathrm{Mg}$ could be useful in young subjects, even if not deficient in $\mathrm{Mg}$ in the blood. In Austria, 24 men with an age range of 27-36 years participated in a 30-day case-control study with the aim of evaluating how oral supplementation of a moderate dose of $\mathrm{Mg}$ can suppress bone turnover rates. The subjects were divided into 2 groups: 12 men took a daily oral dose of $15 \mathrm{mmol}$ of $\mathrm{Mg}$ in the form of a powder, containing $670 \mathrm{mg}$ of $\mathrm{Mg}$ carbonate precipitate (equivalent to $169 \mathrm{mg}$ of $\mathrm{Mg}$ ) and $342 \mathrm{mg}$ of oxide of $\mathrm{Mg}$ (equivalent to $196 \mathrm{mg}$ ), dissolved in $250 \mathrm{ml}$ of drinking water, taken in the early afternoon, with a fasting period of $2 \mathrm{~h}$ before and after taking, while the other 12 , considered as controls, took a glass of water every day in the afternoon after a 2-h fast. In this case, supplementation with $\mathrm{Mg}$ significantly reduced the serum level of the parathyroid hormone. $\mathrm{Mg}$ supplementation also reduced the levels of biochemical markers of both serum formation and reabsorption after 1-5 days (Dimai et al. 1998).

Considering the role of $\mathrm{Mg}$ also in the correct bone growth, analysis were conducted on teenagers, especially female. Carpenter and collaborators conducted a prospective, double-blind, randomized, placebo-controlled, one-year study in which 50 teenage girls were divided into 2 groups: 23 of them had to take $1 \mathrm{cp}$ twice a day containing $\mathrm{Mg}$ oxide powder (300 mg of elemental Mg per day), while other 27 of methylcellulose powder encapsulated with the same dosage. In the group with $\mathrm{Mg}$ supplementation, there was a significant increase in hip bone mineral content. Lumbar spinal bone mineral content was also slightly (but not significantly) higher in the $\mathrm{Mg}$ group (Carpenter et al. 2006). In addition to the supplementation of $\mathrm{Mg}$ only, the mix with other minerals has also proven effective in the development and mineralization of bone in pre-adolescent girls. This is what emerges from a study conducted in Salt Lake City, Utah, in which 81 girls, with an average age of 12 years, were divided into 2 groups for 1 year: a group of 38 girls hired a chewable vitamin/mineral supplement, with a dosage of $4 \mathrm{cp} /$ day, as follows: $800 \mathrm{mg} /$ day of elemental Calcium (as calcium citrate and carbonate), $400 \mathrm{mg} /$ day of elemental $\mathrm{Mg}$ (as $\mathrm{Mg}$ 


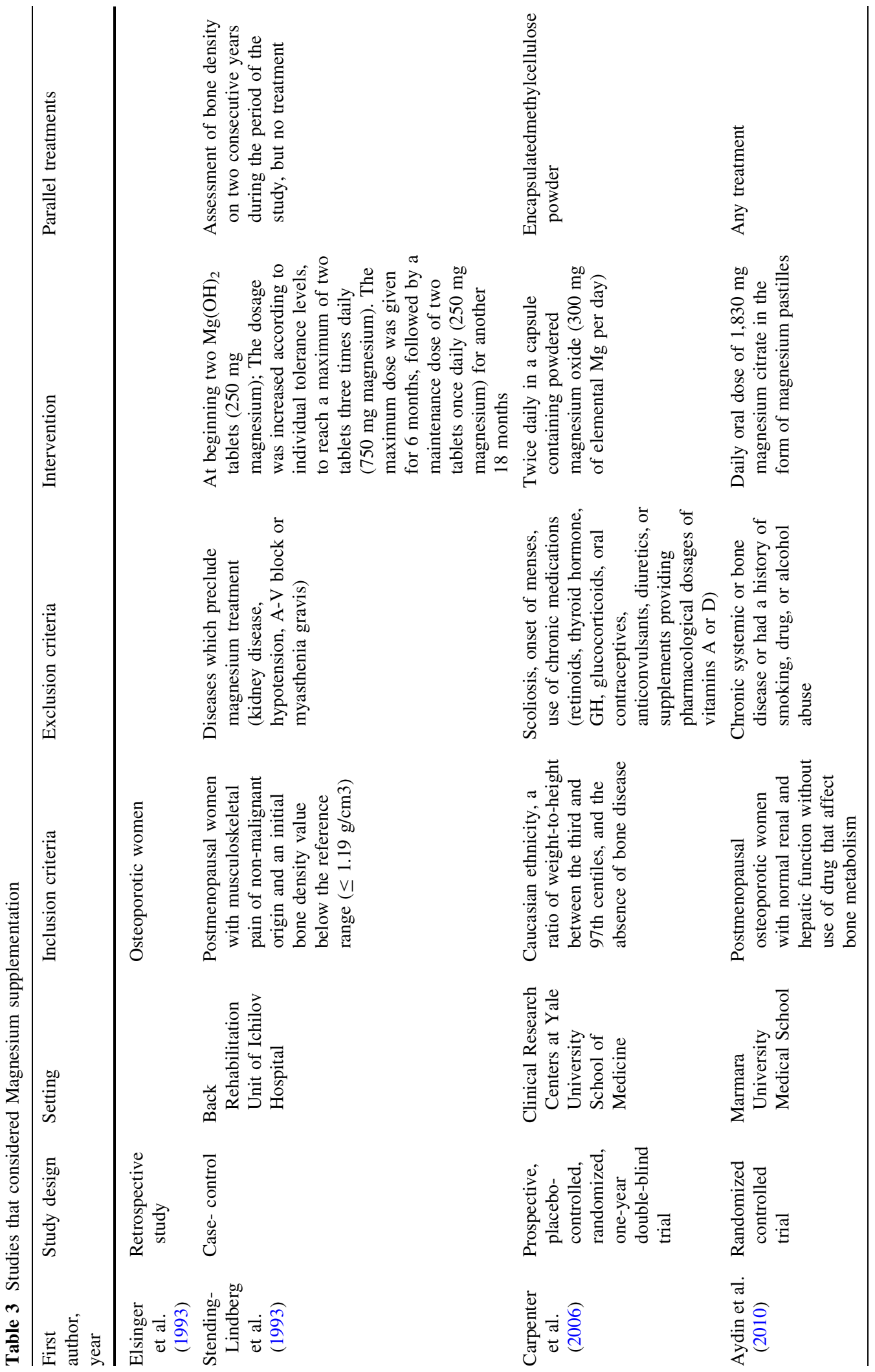




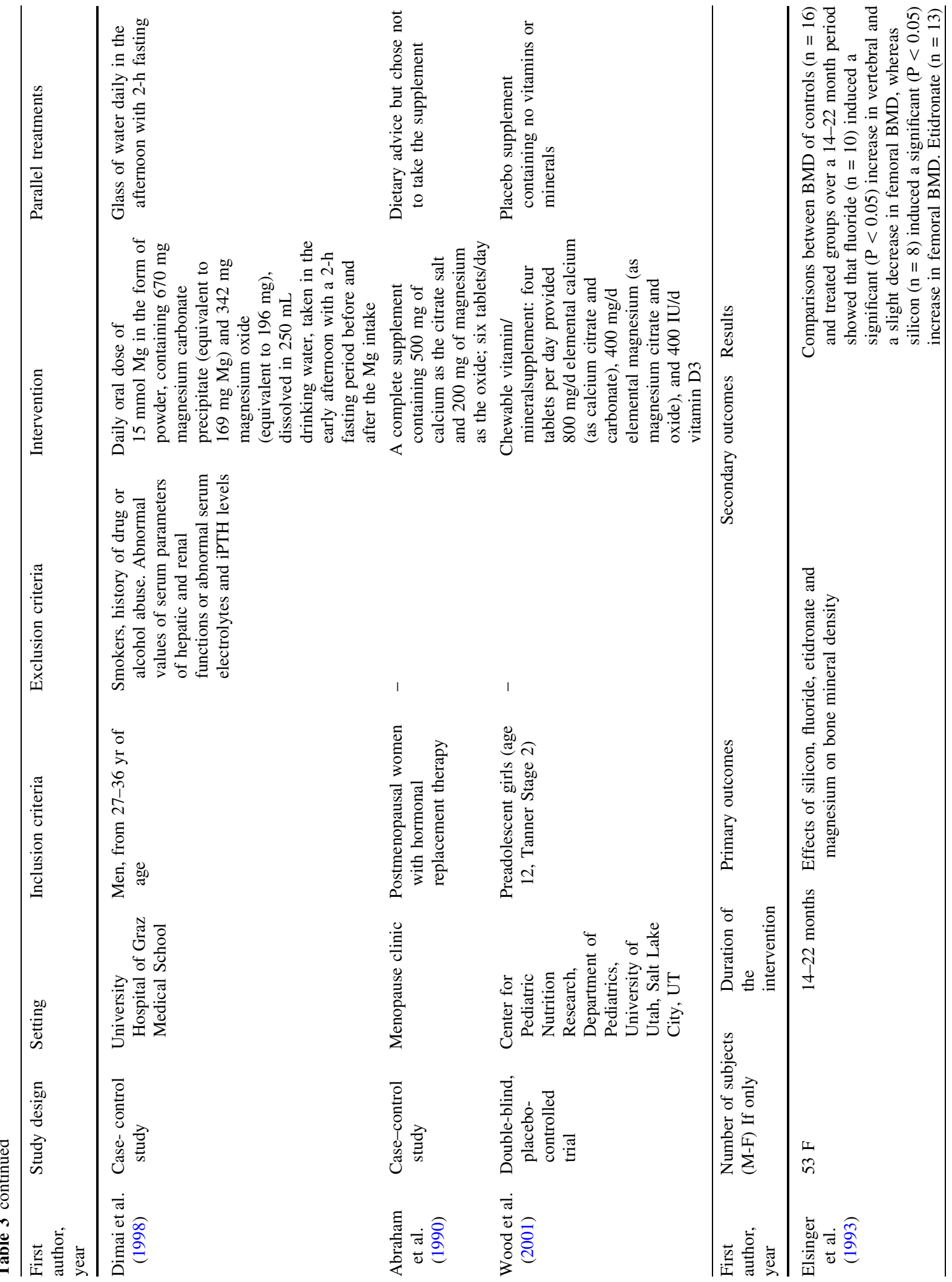




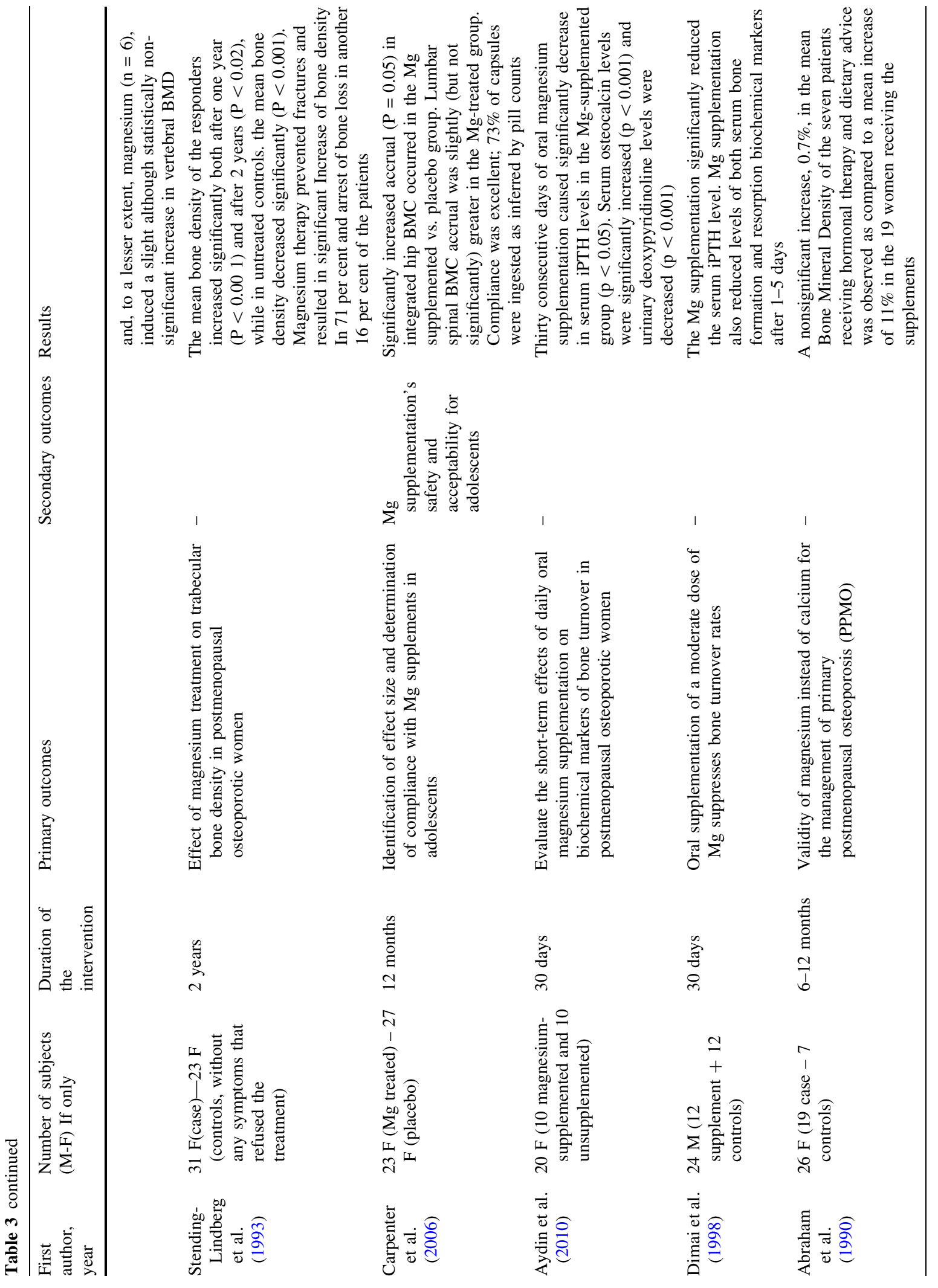


citrate and oxide) and 400 IU/day of vitamin D3, while the other group of 43 girls took a supplement (placebo) without vitamins or minerals. Girls in the supplement group showed a net gain in trabecular bone mineral density of $1.41 \%$ from baseline, while girls in the placebo group showed a net, statistically significant decline of $-0.94 \%$. Furthermore, the increase in $\%$ of the trabecular bone mineral content, after 12 months of integration, was greater in the supplemented group compared to the placebo group (5.83\% versus $0.69 \%$ respectively) (Wood and Mckinnon 2001).

In conclusion, considering the studies published to date on supplementation with $\mathrm{Mg}$, most have used this mineral in the form of citrate, carbonate or oxide, with a dosage varying between 250 and $1800 \mathrm{mg}$, therefore beyond UL. In all studies there was a benefit both in terms of bone mineral density and fracture risk.

\section{Conclusions}

The recommended intake levels (RDA) of Mg were provided by the United States Food and Nutrition Board (Food and Nutrition Board 1997). These values are generally higher in men than women, and in certain situations, such as pregnancy or breastfeeding. More precisely, in the adult man the reference value varies from 400 to $430 \mathrm{mg} / \mathrm{day}$, while in the adult woman the reference value varies from 310 to $320 \mathrm{mg} / \mathrm{day}$. The tolerable upper intake level (UL), in relation to pharmacological contributions or supplementation, is defined for all categories except for the age groups 6-12 months and 1-3 years (for lack of experimental evidence) with a value of $250 \mathrm{mg} / \mathrm{day}$, according to the recommendations of the EFSA document (European Food Safety Authority 2006).

From the various studies carried out since 2009 on the serum concentration of $\mathrm{Mg}$ and its relationship with the bone, it has been shown that lower values are related to the presence of osteoporosis, and that about $30-40 \%$ of the subjects analyzed (mainly menopausal women) have hypomagnesaemia.

Various dietetic investigations carried out have shown that many people (about 20\%) constantly consume lower quantities of $\mathrm{Mg}$ than recommended; moreover, in this category, a lower bone mineral density and a higher fracturing risk have been found several times. 
Considering the studies published to date on supplementation with $\mathrm{Mg}$, most have used this mineral in the form of citrate, carbonate or oxide, with a dosage varying between 250 and $1800 \mathrm{mg}$, therefore beyond UL. In all studies there was a benefit both in terms of bone mineral density and fracture risk.

Funding Open access funding provided by Università degli Studi di Pavia within the CRUI-CARE Agreement. Not applicable.

\section{Compliance with ethical standards}

Conflicts of interest The authors declare no conflicts of interest.

Open Access This article is licensed under a Creative Commons Attribution 4.0 International License, which permits use, sharing, adaptation, distribution and reproduction in any medium or format, as long as you give appropriate credit to the original author(s) and the source, provide a link to the Creative Commons licence, and indicate if changes were made. The images or other third party material in this article are included in the article's Creative Commons licence, unless indicated otherwise in a credit line to the material. If material is not included in the article's Creative Commons licence and your intended use is not permitted by statutory regulation or exceeds the permitted use, you will need to obtain permission directly from the copyright holder. To view a copy of this licence, visit http://creativecommons.org/licenses/by/4.0/.

\section{References}

Abraham GE, Grewal H (1990) A total dietary program emphasizing magnesium instead of calcium. Effect on the mineral density of calcaneous bone in postmenopausal women on hormonal therapy. J Reprod Med 35:503-507

Abrams SA, Chen Z, Hawthorne KM (2014) Magnesium metabolism in 4-year-old to 8-year-old children. J Bone Miner Res 29:118-122. https://doi.org/10.1002/jbmr.2021

Aydin H, Deyneli O, Yavuz D et al (2010) Short-term oral magnesium supplementation suppresses bone turnover in postmenopausal osteoporotic women. Biol Trace Elem Res 133:136-143. https://doi.org/10.1007/s12011-009-8416-8

Carnovale E, Marletta L (2013) Tabelle di composizione degli alimenti

Carpenter TO, DeLucia MC, Zhang JH et al (2006) A randomized controlled study of effects of dietary magnesium oxide supplementation on bone mineral content in healthy girls. J Clin Endocrinol Metab 91:4866-4872. https://doi. org/10.1210/jc.2006-1391

Castiglioni S, Cazzaniga A, Albisetti W, Maier JAM (2013) Magnesium and osteoporosis: Current state of knowledge and future research directions. Nutrients 5:3022-3033

Coudray C, Demigné C, Rayssiguier Y (2003) Effects of Dietary Fibers on Magnesium Absorption in Animals and Humans. J Nutr 133:1-4. https://doi.org/10.1093/jn/133.1.1
Coudray C, Rambeau M, Feillet-Coudray C et al (2005) Dietary inulin intake and age can significantly affect intestinal absorption of calcium and magnesium in rats: a stable isotope approach. Nutr J 4:29. https://doi.org/10.1186/14752891-4-29

Dilworth LL, Omoruyi FO, Asemota HN (2007) In vitro availability of some essential minerals in commonly eaten processed and unprocessed Caribbean tuber crops. Biometals 20:37-42. https://doi.org/10.1007/s10534-0069012-4

Dimai HP, Porta S, Wirnsberger G et al (1998) Daily oral magnesium supplementation suppresses bone turnover in young adult males. J Clin Endocrinol Metab 83:2742-2748. https://doi.org/10.1210/jcem.83.8.5015

Egger M, Dickersin K, Smith GD (2008) Problems and Limitations in Conducting Systematic Reviews. Systematic Reviews in Health Care. BMJ Publishing Group, London, UK, pp 43-68

Eisinger J, Clairet D (1993) Effects of silicon, fluoride, etidronate and magnesium on bone mineral density: a retrospective study. Magnes Res 6:247-249

Elshal MF, Bernawi AE, Al-Ghamdy MA, Jalal JA (2012) The association of bone mineral density and parathyroid hormone with serum magnesium in adult patients with sicklecell anaemia. Arch Med Sci 8:270-276. https://doi.org/10. 5114/aoms.2012.28554

Erem S, Atfi A, Razzaque MS (2019) Anabolic effects of vitamin D and magnesium in aging bone. J Steroid Biochem Mol Biol 193

Esterle L, Sabatier J-P, Guillon-Metz F et al (2009) Milk, rather than other foods, is associated with vertebral bone mass and circulating IGF-1 in female adolescents. Osteoporos Int 20:567-575. https://doi.org/10.1007/s00198-008-0708-x

European Food Safety Authority (2006) Tolerable upper intake levels for vitamins and minerals. Scientific Committee on Food; Scientific Panel on Dietetic Products, Nutrition and Allergies

European Food Safety Authority (2009) Scientific Opinion on the substantiation of health claims related to magnesium and electrolyte balance (ID 238), energy-yielding metabolism (ID 240, 247, 248), neurotransmission and muscle contraction including heart muscle (ID 241, 242), cell division. EFSA J. https://doi.org/10.2903/j.efsa.2009.1216

Farrell VA, Harris M, Lohman TG et al (2009) Comparison between dietary assessment methods for determining associations between nutrient intakes and bone mineral density in postmenopausal women. J Am Diet Assoc 109:899-904. https://doi.org/10.1016/j.jada.2009.02.008

Food and Nutrition Board (1997) Dietary reference intakes for calcium, phosphorus, magnesium, vitamin D, and fluoride

Gunn CA, Weber JL, Kruger MC (2014) Diet, weight, cytokines and bone health in postmenopausal women. J Nutr Health Aging 18:479-486. https://doi.org/10.1007/s12603-0140002-x

Hayhoe RPG, Lentjes MAH, Luben RN et al (2015) Dietary magnesium and potassium intakes and circulating magnesium are associated with heel bone ultrasound attenuation and osteoporotic fracture risk in the EPIC-Norfolk cohort study. Am J Clin Nutr 102:376-384. https://doi.org/10. 3945/ajcn.114.102723 
Huang J-H, Cheng F-C, Wu H-C (2015) Low magnesium exacerbates osteoporosis in chronic kidney disease patients with diabetes. Int J Endocrinol 2015:380247. https://doi. org/10.1155/2015/380247

Kim M-H, Yeon J-Y, Choi M-K, Bae YJ (2011) Evaluation of magnesium intake and its relation with bone quality in healthy young Korean women. Biol Trace Elem Res 144:109-117. https://doi.org/10.1007/s12011-011-9044-7

Kunutsor SK, Whitehouse MR, Blom AW, Laukkanen JA (2017) Low serum magnesium levels are associated with increased risk of fractures: a long-term prospective cohort study. Eur J Epidemiol 32:593-603. https://doi.org/10. 1007/s10654-017-0242-2

Leclercq C, Arcella D, Piccinelli R et al (2009) The italian national food consumption survey INRAN-SCAI 2005-06: main results in terms of food consumption. Public Health Nutr 12:2504-2532. https://doi.org/10.1017/ S1368980009005035

Lönnerdal B (1997) Effects of milk and milk components on calcium, magnesium, and trace element absorption during infancy. Physiol Rev 77:643-669. https://doi.org/10.1152/ physrev.1997.77.3.643

Mahdavi-Roshan M, Ebrahimi M, Ebrahimi A (2015) Copper, magnesium, zinc and calcium status in osteopenic and osteoporotic post-menopausal women. Clin Cases Miner Bone Metab 12:18-21. https://doi.org/https://doi.org/10. $11138 / \mathrm{ccmbm} / 2015.12 .1 .018$

Matias CN, Santos DA, Monteiro CP et al (2012) Magnesium intake mediates the association between bone mineral density and lean soft tissue in elite swimmers. Magnes Res 25:120-125. https://doi.org/10.1684/mrh.2012.0317

Mederle OA, Balas M, Ioanoviciu SD et al (2018) Correlations between bone turnover markers, serum magnesium and bone mass density in postmenopausal osteoporosis. Clin Interv Aging 13:1383-1389. https://doi.org/10.2147/CIA. S170111

Navarro-González JF, Mora-Fernández C, García-Pérez J (2009) Clinical implications of disordered magnesium homeostasis in chronic renal failure and dialysis. Semin Dial 22:37-44. https://doi.org/10.1111/j.1525-139X.2008. 00530.x

Okyay E, Ertugrul C, Acar B et al (2013) Comparative evaluation of serum levels of main minerals and postmenopausal osteoporosis. Maturitas 76:320-325. https://doi.org/10. 1016/j.maturitas.2013.07.015

Orchard TS, Larson JC, Alghothani N et al (2014) Magnesium intake, bone mineral density, and fractures: results from the Women's Health Initiative Observational Study. Am J Clin Nutr 99:926-933. https://doi.org/10.3945/ajcn.113.067488
Rai SP, Sharma R (2016) Magnesium as an important marker in post-menopausal women with osteoporosis and osteopenia. Int J Pharm Sci Invent ISSN 5:1-3

Razzaque MS (2018) Magnesium: are we consuming enough? Nutrients 10:1-8. https://doi.org/10.3390/nu10121863

Roth P, Werner E (1979) Intestinal absorption of magnesium in man. Int J Appl Radiat Isot 30:523-526. https://doi.org/10. 1016/0020-708X(79)90164-9

Seelig M (1981) Magnesium requirements in human nutrition. Magnes Bull 3:26-47

Sharma R, Sharma P, Kumar P, Gupta G (2016) Role of magnesium in post-menopausal women with osteoporosis and osteopenia. Asian J Pharm Clin Res 9:198-199

Stendig-Lindberg G, Tepper R, Leichter I (1993) Trabecular bone density in a two year controlled trial of peroral magnesium in osteoporosis. Magnes Res 6:155-163

Teo K, Chow CK, Vaz M et al (2009) The Prospective Urban Rural Epidemiology (PURE) study: examining the impact of societal influences on chronic noncommunicable diseases in low-, middle-, and high-income countries. Am Heart J 158:1-7.e1. https://doi.org/10.1016/j.ahj.2009.04. 019

US Department of Agriculture (2009) Nutrient Database for Standard Reference, Realase 22

US Department of Agriculture (2019) Usual Nutrient Intake from Food and Beverages, by Gender and Age, What We Eat in America, NHANES 2013-2016

Uwitonze AM, Razzaque MS (2018) Role of magnesium in vitamin d activation and function. J Am Osteopath Assoc 118:181-189

Veronese N, Stubbs B, Solmi M et al (2017) Dietary magnesium intake and fracture risk: Data from a large prospective study. Br J Nutr 117:1570-1576. https://doi.org/10.1017/ S0007114517001350

Welch AA, Skinner J, Hickson M (2017) Dietary magnesium may be protective for aging of bone and skeletal muscle in middle and younger older age men and women: crosssectional findings from the uk biobank cohort. Nutrients. https://doi.org/10.3390/nu9111189

Wood T, Mckinnon T (2001) Calcium-Magnesium-Vitamin D Supplementation Improves Bone Mineralization in Preadolescent Girls

Wright HH, Kruger MC, Schutte WD et al (2019) Magnesium intake predicts bone turnover in postmenopausal Black South African women. Nutrients. https://doi.org/10.3390/ nu11102519

Publisher's Note Springer Nature remains neutral with regard to jurisdictional claims in published maps and institutional affiliations. 